\title{
Immunohistochemistry of proteins for DNA mismatch repair in correlation to prognostic factors of mammarian cancer
}

\author{
FRANK KÖSTER $^{1}$, ANDREAS SCHRÖER ${ }^{1}$, DOROTHEA FISCHER ${ }^{1}$, \\ ANJA-KATHRIN HORN ${ }^{2}$, KLAUS DIEDRICH ${ }^{1}$ and MICHAEL FRIEDRICH ${ }^{1}$ \\ ${ }^{1}$ Department of Obstetrics and Gynecology, UK S-H, Campus Luebeck, Ratzeburger Allee 160, D-23538 Luebeck; \\ ${ }^{2}$ Department of Obstetrics and Gynecology, University of Saarland, D-66421 Homburg/Saar, Germany
}

Received November 29, 2006; Accepted January 15, 2007

\begin{abstract}
Mutations in genes of the DNA mismatch repair system (MMR) are strongly linked to the development of hereditary non-polyposis colorectal cancer and play a significant role in sporadic cancer too. Besides the repair of chromosomal mismatches produced during replication, the MMR is the linkage of DNA mismatches to cell cycle control. Proteins of the MMR are necessary for the induction of apoptosis in response to non-tolerable amounts of DNA damage. We correlated the immunoreactivity of the MMR proteins hMSH2, hMLH1 and PMS2 to the immunoreaction of p53, the proliferation marker Ki67 and clinical prognosis factors such as tumor grading and staging, steroid receptor expression and hemangiosis carcinomatosa or lymphangiosis carcinomatosa in 200 samples from patients with diagnosed breast cancer. No correlation could be detected among the expression of the three MMR-proteins hMSH2, hMLH1 and PMS2. The expression of hMSH2 correlated positively with the expression of $\mathrm{p} 53$, with the appearance of distant metastases, low differentiation and the appearance of hemangiosis carcinomatosa and lymphangiosis carcinomatosa, while it negatively correlated with the expression of the estrogen receptor. No correlation was detected between hMLH1 or PMS2 and any of the investigated factors. The expression of hMSH2 seems to be related with predictors of an unfavorable course of disease in breast cancer.
\end{abstract}

\section{Introduction}

Breast cancer is one of the most common malignancies in females of the western countries. The prognosis for patients with diagnosed breast cancer depends on a series of prognostic

Correspondence to: Dr Frank Köster, Department of Obstetrics and Gynecology, UK S-H, Campus Luebeck, Ratzeburger Allee 160, D-23538 Luebeck, Germany

E-mail: frank-hl@web.de

Key words: breast cancer, DNA mismatch repair, p53, immunohistochemistry factors. Among these, tumor size and grade, lymph nodes and metastases have a great prognostic value while the expression of hormone receptors and ERBB2/neu status have more a predictive value on therapeutic options. Proliferation index, S-phase index and expression of the tumor suppressor protein p53 are further useful factors. Alternatively, the proteins for DNA mismatch repair (MMR) have also gained interest in breast cancer. The MMR genes are known as the mutator in hereditary nonpolyposis colon carcinoma (HNPCC) where mutations in human Mut-S-Homologon-2 (hMSH2), human Mut-L-Homologon-1 (hMLH1) and postmeiotic segregation-2 (PMS2) occur most frequently. While MMR mutations in HNPCC are strongly linked to microsatellite instability (MSI), deregulations of MMR proteins do not necessarily correlate with MSI in sporadic cancer (1-4). Alterations of MMR protein expression have been detected in various gynecological tumors, i.e. in endometrial cancer $(5,6)$, ovarian cancer $(7,8)$, malignancies of the uterine corpus (9) and breast cancer (10-12).

The main function of the MMR is the repair of DNA mismatches during replication and homologous recombination. Further, it is involved in the signaling of DNA damage to proteins of cell cycle control such as p53 and the induction of apoptosis. This is demonstrated in MMR-deficient cells tolerating DNA damage produced by UV radiation or cytostatics without the induction of apoptosis. Scherer et al (13) identified a response element for p53 in the promoter region of the hMSH2 gene and Warnick et al showed that p53 actively regulates the hMSH2 expression in ovarian cancer cells (14). Point mutations in hMSH2 have shown that the mismatch repair function of $\mathrm{hMSH} 2$ appears to be independent from its ability to induce cell death after cisplatin exposure $(15,16)$. The relationsip between hMSH2 and p53 was investigated in various studies with diverse outcome in different cancer populations. Rass et al (17) found increased immunoreactive scores in malignant melanoma for both, hMSH2 and p53 whereas Spagnoletti et al found that hMSH2-positive tumor cells tended to be negative for the expression of p53 in breast cancer (4).

In this study we describe the relationship between the expression of the MMR proteins hMSH2, hMLH1, PMS2 to p53 and the proliferation marker Ki67 in 200 samples of mammarian cancer. Further, we correlate these results with prognostic factors in breast cancer such as steroid receptor 
Table I. Description of the patient population and key clinicopathological data.

\begin{tabular}{|c|c|}
\hline Age of patients & mean, 60.3 years; range, $30-89$ years \\
\hline Tumour stage & pT1,32\%; pT2, 40\%; pT3, 9.6\%; pT4, 16.3\% \\
\hline Lymph nodes $(\leq \mathrm{N} 1)$ & $49 \%$ \\
\hline Distant metastasis $(\leq \mathrm{M} 1)$ & $23.2 \%$ \\
\hline Differentiation & low, 55.1\%; medium, 44.9; high, 0 \\
\hline Histological classification & ductal, $68 \%$; lobular, $15.8 \%$; others, $15.2 \%$ \\
\hline Hemangiosis carcinomatosa & $10.2 \%$ \\
\hline Lymphangiosis carcinomatosa & $27.8 \%$ \\
\hline Estrogen receptor expression & $66.1 \%$ \\
\hline Progesterone receptor expression & $47.8 \%$ \\
\hline p53 positive & $67.6 \%$ \\
\hline Ki67 positive & $61.1 \%$ \\
\hline
\end{tabular}

status, TNM-stage, cell differentiation and the appearance of hemangiosis carcinomatosa and lymphangiosis carcinomatosa.

\section{Materials and methods}

The investigations on human material were approved by the ethics committee of the University of Homburg/Saar. Each patient was informed and asked for her consent to participate in this study. Residues of tumor samples have been collected after histological examinations by pathologists. Grading and staging of the tumors, the status of steroid receptors and the appearance of cacinomatosa hemangiosis and carcinomatosa lymphangiosis were taken from the pathologists' reports.

Tissue specimens. Two hundred tumor tissues from 186 patients with mammarian cancer were collected and shock frozen in liquid nitrogen. Serial sections of 5- $\mu \mathrm{m}$ thickness were cut with a cryostat microtome and mounted on microscopic slides. The glass slides were previously coated with 3-(triethoxysilyl)propylamine (Merck, Frankfurt, Germany). After mounting, the tissue sections were kept at $-80^{\circ} \mathrm{C}$ until use for immunohistochemistry. Fixation was performed for $10 \mathrm{~min}$ in Zambonifixation solution containing $15 \%$ saturated picric acid solution and $2 \%$ paraformaldehyde in phosphate-buffered saline (PBS). Slides were washed in PBS.

Immunohistochemistry. Unspecific protein binding was blocked with normal sera from rabbit (Dako, Hamburg, Germany Code-No. M0722, 1:50 in Tris-buffer) for $15 \mathrm{~min}$. Against hMSH2 we used the monoclonal mouse antibody clone FE-11 in a 1:100 dilution (Calbiochem, Merck Biosciences, Schwalbach, Germany), against MLH1 the monoclonal antibody clone G168-728 (Pharmingen, BD Biosciences, Heidelberg, Germany), against p53 the monoclonal mouse antibody clone DO-7 in a 1:150 dilution and for Ki67 the polyclonal rabbit antibody A-047 in 1:50 dilution (both Dako). The tumor sections were incubated with primary antibodies at $4^{\circ} \mathrm{C}$ overnight together with fish gelatin $(1: 100)$ for blocking unspecific binding.

The immunodetection was performed using the $\mathrm{ABC}$ method (Dako). The secondary biotinylated antibody was incubated at a 1:200 dilution for $25 \mathrm{~min}$ at $37^{\circ} \mathrm{C}$ followed by the streptavidin-biotin complex for $25 \mathrm{~min}$ at $37^{\circ} \mathrm{C}$ and an amplification reaction with streptavidin-peroxidase and biotinyl-tyramine for another $15 \mathrm{~min}$ at $37^{\circ} \mathrm{C}$. Three wash steps were performed after each incubation. The peroxidase activity was visualized with 3,3'-diaminobenzidine (DAB) (Dako).

Interpretation of the immunoreactivity. The interpretation of the immunoreactivity in tumor sections was performed using the immunoreactive score (IRS) described by Remmele and Stegner (18). The IRS results from the multiplication of a staining intensity score (negative, 0 ; weak, 1; moderate, 2; strong, 3) and the percentage score of immunopositive cells (SI- negative, 0 ; weak, 1; moderate, 2; strong, 3 ). The immunoreactivity for Ki67 was evaluated and compared with other immunoreactivities with a scoring after Friedrich et al (9) that creates a ranking of the percentages of immunopositive cells (PP) (rank $0,0 \% ; 1,1-10 \% ; 2,11-25 \% ; 3,>25 \%)$.

Microscopy and photography. The immunoassayed specimens were viewed under a Leica DM4000 microscope and photographed using an SIS Colorview 12 digital camera.

Statistical analysis of correlation. The statistical correlations among hMSH2, p53 and Ki67 immunoreactivity were analyzed by Spearman's rank correlation coefficient in SPSS version 10.0 . The statistical significance was set to $p<0.05$. To correlate the mismatch repair protein expression with prognostic factors of the patients we used the $\chi^{2}$-test.

\section{Results}

We investigated the expression of the MMR proteins hMSH2, hMLH1 and PMS2 by immunohistochemistry. An overview of the patient population with an excerpt of clinicopathologic data is given in Table I. Of 200 tumor sections, 195 (97.5\%) showed positive immunoreactions for hMSH2, $173(86.5 \%)$ were positive for hMLH1, and 53 of 56 sections (94.6\%) stained positive with the antibody against PMS2. Examples of immunoassayed slides are shown in Fig. 1. 


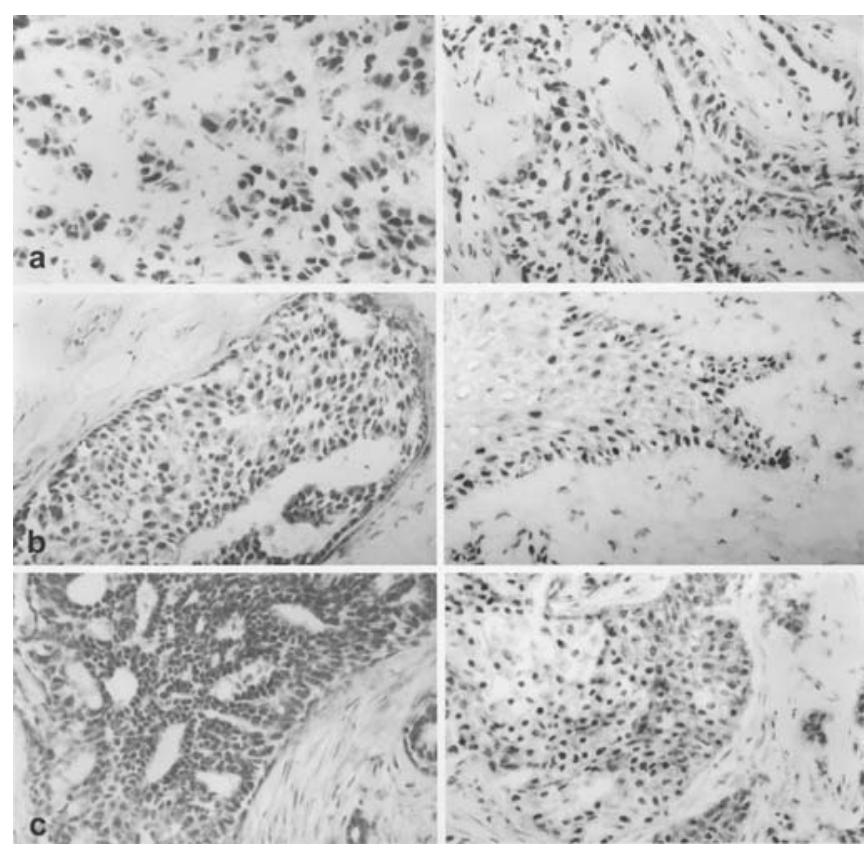

Figure 1. Immunohistochemistry of samples from mammarian carcinoma. Magnification, x400. (a) hMSH2 detection: left, sample with $84 \%$ immunoreactive tumor cells (PP) and an immunoreactive score (IRS) of 12; and right, sample with $\mathrm{PP}=70 \%$ and IRS=6. (b) hMLH1 detection: left, sample with $\mathrm{PP}=80 \%, \mathrm{IRS}=9$; and right, sample with $\mathrm{PP}=48 \%$, IRS=6. (c) Detection of PMS2: left, sample with $\mathrm{PP}=97 \%$, IRS $=12$; and right, sample with $\mathrm{PP}=82 \%$ and $\mathrm{IRS}=4$

Correlation between MMR proteins. There were no correlations between the immunoreactive scores (IRS) of the MMR proteins hMSH2, hMLH1 and hPMS2 analyzed by the Spearman's rank correlation coefficient. The data are summarized in Table II.

Correlation of MMR proteins with the proliferation marker Ki67. To determine if the MMR protein upregulation results from the elevated proliferating activity in tumor tissue, we correlated it with the expression of the proliferation marker Ki67. No correlation between the immunoreactivity of the proliferation marker Ki67 and any of the immunoreactions for MMR proteins was found (Table III).

Correlation of MMR proteins with the tumor suppressor protein p53. Of 179 tumor tissues, 121 (67.6\%) tested for p53 immunoreactivity were stained positive. The IRS for
Table II. Spearman's rank correlation coefficients between the immunoreactive scores of the mismatch repair proteins hMSH2, hMLH1 and PMS2.

\begin{tabular}{lcc}
\hline $\begin{array}{l}\text { Spearman's rank } \\
\text { correlation coefficient }\end{array}$ & hMLH1-IRS & PMS2-IRS \\
\hline hMSH2-IRS ( $=200)$ & $0.118(\mathrm{p}=0.095)$ & $-0.130(\mathrm{p}=0.34)$ \\
hMLH1-IRS $(\mathrm{n}=200)$ & & $0.098(\mathrm{p}=0.473)$ \\
\hline
\end{tabular}

hMSH2 correlated with the IRS for p53 significantly with a low Spearman's rank correlation coefficient of $0.211(\mathrm{p}=0.005)$ while hMLH1 and hPMS2 did not correlate with the p53 expression (Table III).

Correlation of the MMR protein expression with the immunoreactivity for steroid receptors. According to Table III, the Spearman's rank correlation coefficient for the relationship between hMSH2-IRS and the IRS of the estrogen receptor (ER) showed a weak negative correlation ( $\mathrm{rs}=-0.184, \mathrm{p}=0.014)$. Of 173 samples, 121 (66.1\%) were ER-positive. No further correlation was found between any of the MMR proteins and ER or progesterone receptor (PR) expression. Of the 184 examined tissue sections, $47.8 \%$ were PR-positive.

Correlation of the MMR protein expression with known prognostic tumor factors. The IRS for hMSH2 correlated significantly with the presence of distant metastases $(\mathrm{p}=0.009$, $\chi^{2}$-test), while the IRS for hMLH1 and PMS2 did not. Of 186 patients, $23.2 \%$ had distant metastases, as shown in Table IV. We could not detect any correlation between the expression of proteins of the MMR and histological tumor stage or the appearance of lymph nodes. Tissues with a low grade of differentiation had a significantly higher IRS for hMSH2 ( $\mathrm{p}=0.001, \chi^{2}$-test), while the IRS for hMLH1 and PMS2 did not correlate with the grade of differentiation. One hundred and seven $(55.1 \%)$ of the tumor sections were described as low-differentiated and 83 (44.9\%) were medium-differentiated, while no strong-differentiated tumors were identified.

Correlation of the hMSH2-IRS with hemangiosis carcinomatosa and lymphangiosis carcinomatosa. Of the patients, $10.2 \%$ were diagnosed positive for hemangiosis carcinomatosa and $27.8 \%$ for lymphangiosis carcinomatosa. The IRS for hMSH2

Table III. Correlation of the immunoreactive scores of mismatch repair proteins with the immunoreactivities of Ki67, p53 and the steroid receptors for estrogen (ER) and progesterone (PR).

\begin{tabular}{lcccr}
\hline Spearman's rank correlation coefficient & Ki67 $(\mathrm{n}=173)$ & $\mathrm{p} 53(\mathrm{n}=179)$ & ER $(\mathrm{n}=173)$ & PR $(\mathrm{n}=184)$ \\
\hline hMSH2 $(\mathrm{n}=200)$ & $-0.008(\mathrm{p}=0.914)$ & $0.211^{\mathrm{a}}(\mathrm{p}=0.005)$ & $-0.182^{\mathrm{a}}(\mathrm{p}=0.014)$ & $-0.1(\mathrm{p}=0.178)$ \\
hMLH1 $(\mathrm{n}=200)$ & $0.023(\mathrm{p}=0.968)$ & $0.094(\mathrm{p}=0.212)$ & $0.003(\mathrm{p}=0.97)$ & $0.143(\mathrm{p}=0.053)$ \\
hPMS2 $(\mathrm{n}=56)$ & $0.037(\mathrm{p}=0.807)$ & $0.215(\mathrm{p}=0.112)$ & $0.014(\mathrm{p}=0.916)$ & $0.04(\mathrm{p}=0.771)$ \\
\hline
\end{tabular}

a Statistically significant. 
Table IV. Correlations of the immunoreactive scores for mismatch repair proteins with prognostic factors in breast cancer using the $\chi^{2}$-test.

\begin{tabular}{lccc}
\hline$\chi^{2}$-test & hMSH2-IRS $(\mathrm{n}=200)$ & hMSH2-IRS (n=200) & hPMS2-IRS (n=56) \\
\hline Tumor grading & $\mathrm{p}=0.890$ & $\mathrm{p}=0.391$ & $\mathrm{p}=0.894$ \\
Lymph nodes & $\mathrm{p}=0.245$ & $\mathrm{p}=0.534$ & $\mathrm{p}=0.174$ \\
Distant metastases & $\mathrm{p}=0.009^{\mathrm{a}}$ & $\mathrm{p}=0.531$ & $\mathrm{p}=0.345$ \\
Differentiation & $\mathrm{p}=0.001^{\mathrm{a}}$ & $\mathrm{p}=0.153$ & $\mathrm{p}=0.745$ \\
Hemangiosis carcinomatosa $(\mathrm{n}=189)$ & $\mathrm{p}=0.017^{\mathrm{a}}$ & $\mathrm{p}=0.924$ & $\mathrm{p}=0.782$ \\
Lymphangiosis carcinomatosa $(\mathrm{n}=189)$ & $\mathrm{p}=0.048^{\mathrm{a}}$ & $\mathrm{p}=0.988$ & $\mathrm{p}=0.343$ \\
\hline
\end{tabular}

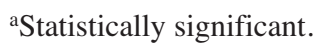

correlated significantly with the appearance of hemangiosis $\left(\mathrm{p}=0.017, \chi^{2}\right.$-test $)$ and lymphangiosis $\left(\mathrm{p}=0.048, \chi^{2}\right.$-test $)$. The IRS for hMLH1 and PMS2 did not correlate with the appearance of hemangiosis or lymphangiosis (Table IV).

\section{Discussion}

The role of MMR proteins in cancer is widely discussed. In HNPCC related cancer with mutations in MMR genes there is a close association between the loss of MMR function and tumor development. In sporadic cancer without a primary MMR gene mutation the function of the MMR system could be important for the tumorigenesis too. Our previous studies revealed elevated hMSH2 levels in tumors of the breast compared to normal tissue (12). Other studies report an upregulation of MMR expression with a peak in noninvasive carcinoma or low-grade tumors $(19,20)$. Here, we correlated the immunoreactivity of the MMR proteins hMSH2, hMLH1 and PMS2 with each other and also with the tumor suppressor protein $\mathrm{p} 53$, the proliferation marker Ki67 and known prognostic factors for breast cancer.

In almost every sample (97.5\%) we were able to detect an immunoreaction against hMSH2. The abundance of hMLH1 with $86.5 \%$ was lower compared to hMSH2. Murata et al reported that promoter hypermethylation is in most cases the reason for hMLH1 downregulation in breast cancer (21). Similar proportions for the lack of MMR protein immunoreactivity of hMSH2 (6.5\%) and hMLH1 $(22.3 \%)$ were found by Hardisson et al (22).

We found no correlation between the expression levels of the investigated MMR proteins, while Murata et al detected a correlation between the expression of hMSH2 and hMLH1 in breast cancer tissue (23). They were comparing 'attenuated' and 'normal' expression in 83 breast cancer patients whereas we used the IRS scores with a more sensitive scale of 12 different IRS levels in nearly 200 cases, which could be a possible reason for the different result. Son et al did not find a relationship between the expression levels of $\mathrm{hMSH} 2$ and hMLH1 in breast cancer (24).

The MMR-system is preferably required during the $\mathrm{S}$ phase in proliferation. We correlated the MMR protein expression with the expression of the proliferation marker Ki67 to evaluate if the immunoreactivity of the MMR proteins is simply dependent on the elevated proliferative activity in cancer cells. As we could not detect any correlation between the immunoreactivity for Ki67 and any of the MMR proteins we propose that the cause for the deregulation of MMR proteins in cancer is not related to the increased proliferation activity.

We were further interested in the correlation of MMR protein expression with prognostic factors for mammarian carcinoma. The immunoreactivities of p53 and hMSH2 exhibited a low Spearman's rank correlation coefficient of 0.211. No other correlations between MMR proteins and p53 were detected. Positive p53 immunoreactivity normally predicts a mutated p53 because wild-type p53 is supposed to be hardly detectable resulting from the fast turnover of the p53 protein. In this study, we found p53 immunoreaction in $67 \%$ of all tissues, which does not reflect the general mutation rates of approximately $20-25 \%$. Therefore, we conclude that we probably revealed also the wild-type p53 expression. Also other studies report high percentages of immunodetectable p53, for example that of Spagnoletti et al with $48 \%$ p53 in breast cancer (4) and Cheah et al with over $70 \%$ in cervical carcinoma (25). Assuming that we detected wild-type p53, its correlation with hMSH2 seems to be reliable because p53 is able to regulate the hMSH2 expression by a response element in the hMSH2 promoter $(14,26)$. Spagnoletti et al showed a correlation between the subgroup of p53 immunonegative tumors and a lower percentage of hMSH2-positive samples, but they concluded that p53 immunoreactivity represents its mutation.

The expression of hMSH2 further correlated with the appearance of distant metastases, a low differentiation of tumor cells and the appearance of hemangiosis carcinomatosa and lymphangiosis carcinomatosa. Interestingly, only the hMSH2 expression correlated with factors predicting a more severe progress of the disease. This partially contradicts the results from other groups that found the highest hMSH2 expression in early tumour stages and a minor enhancement in severe tumors. Additionally, we found a weak negative correlation between $\mathrm{hMSH} 2$ and the expression of estrogen receptors. By contrast, Murata et al detected decreased hMSH2 levels in patients with higher tumor stages and the appearance of metastases (23). Spagnoletti et al found no correlation between the hMSH2 expression and any of the 
clinicopathological data except the hormone receptor status. In accordance with our results they found a negative relationship between hMSH2 expression and the hormone receptor status (4).

The best candidate for a prognostic factor under MMRproteins from our results is hMSH2, but as long as the data from the literature are so diverse, this is not of strong value.

\section{References}

1. Adem C, Soderberg CL, Cunningham JM, Reynolds C, Sebo TJ, Thibodeau SN, Hartmann LC and Jenkins RB: Microsatellite instability in hereditary and sporadic breast cancers. Int J Cancer 107: 580-582, 2003.

2. Catto JW, Xinarianos G, Burton JL, Meuth M and Hamdy FC: Differential expression of hMLH1 and hMSH2 is related to bladder cancer grade, stage and prognosis but not microsatellite instability. Int J Cancer 105: 484-490, 2003.

3. Parc YR, Halling KC, Burgart LJ, McDonnell SK, Schaid DJ, Thibodeau SN and Halling AC: Microsatellite instability and $\mathrm{hMLH} 1 / \mathrm{hMSH} 2$ expression in young endometrial carcinoma patients: associations with family history and histopathology. Int J Cancer 86: 60-66, 2000.

4. Spagnoletti I, Pizzi C, Galietta A, Di Maio M, Mastranzo P, Daniele S, Limite G, Pettinato G and Contegiacomo A: Loss of hMSH2 expression in primary breast cancer with p53 alterations. Oncol Rep 11: 845-851, 2004.

5. Friedrich M: Analysis of the DNA 'mismatch-repair' enzyme human mut-S-homologon-2 in endometrial cancer on proteinand RNA-level. Eur J Gynaecol Oncol 21: 273-277, 2000.

6. Salvesen HB, MacDonald N, Ryan A, Iversen OE, Jacobs IJ, Akslen LA and Das S: Methylation of hMLH1 in a populationbased series of endometrial carcinomas. Clin Cancer Res 6: 3607-3613, 2000.

7. Friedrich M, Villena-Heinsen C, Meyberg R, Woll-Hermann A, Reitnauer K, Schmidt W, Tilgen W and Reichrath J: Immunohistochemical analysis of DNA 'mismatch-repair' enzyme human Mut-S-Homologon-2 in ovarian carcinomas. Histochem J 31: 717-722, 1999.

8. Geisler JP, Goodheart MJ, Sood AK, Holmes RJ, HattermanZogg MA and Buller RE: Mismatch repair gene expression defects contribute to microsatellite instability in ovarian carcinoma. Cancer 98: 2199-2206, 2003.

9. Friedrich M, Villena-Heinsen C, Reitnauer K, Schmidt W, Tilgen W and Reichrath J: Malignancies of the uterine corpus and immunoreactivity score of the DNA 'mismatch-repair' enzyme human Mut-S-homologon-2. J Histochem Cytochem 47: 113-118, 1999.

10. Balogh GA, Russo IH and Russo J: Mutations in mismatch repair genes are involved in the neoplastic transformation of human breast epithelial cells. Int J Oncol 23: 411-419, 2003.

11. Bock N, Meden H, Regenbrecht M, Junemann B, Wangerin J and Marx D: Expression of the mismatch repair protein $\mathrm{hMSH} 2$ in carcinoma in situ and invasive cancer of the breast. Anticancer Res 20: 119-124, 2000.

12. Friedrich M, Meyberg R, Villena-Heinsen C, Woll-Hermann A, Reitnauer K, Schmidt W, Tilgen and W Reichrath J: Immunohistochemical analysis of DNA mismatch-repair enzyme hMSH-2 and Ki-67 in breast carcinomas. Anticancer Res 19: 3349-3353, 1999.
13. Scherer SJ, Maier SM, Seifert M, Hanselmann RG, Zang KD, Muller-Hermelink HK, Angel P, Welter C and Schartl M: p53 and c-Jun functionally synergize in the regulation of the DNA repair gene hMSH2 in response to UV. J Biol Chem 275: 37469-37473, 2000.

14. Warnick CT, Dabbas B, Ford CD and Strait KA: Identification of a p53 response element in the promoter region of the hMSH2 gene required for expression in A2780 ovarian cancer cells. J Biol Chem 276: 27363-27370, 2001.

15. Clodfelter JE, M BG and Drotschmann K: MSH2 missense mutations alter cisplatin cytotoxicity and promote cisplatininduced genome instability. Nucleic Acids Res 33: 3323-3330, 2005.

16. Drotschmann K, Topping RP, Clodfelter JE and Salsbury FR: Mutations in the nucleotide-binding domain of MutS homologs uncouple cell death from cell survival. DNA Repair 3: 729-742, 2004.

17. Rass K, Gutwein P, Welter C, Meineke V, Tilgen W and Reichrath J: DNA mismatch repair enzyme hMSH2 in malignant melanoma: increased immunoreactivity as compared to acquired melanocytic nevi and strong mRNA expression in melanoma cell lines. Histochem J 33: 459-467, 2001.

18. Remmele W and Stegner HE: Recommendation for uniform definition of an immunoreactive score (IRS) for immunohistochemical estrogen receptor detection (ER-ICA) in breast cancer tissue. Pathologe 8: 138-140, 1987.

19. Ciavattini A, Piccioni M, Tranquilli AL, Filosa A, Pieramici T and Goteri G: Immunohistochemical expression of DNA mismatch repair (MMR) system proteins (hMLH1, hMSH2) in cervical preinvasive and invasive lesions. Pathol Res Pract 201: $21-25,2005$.

20. Giarnieri E, Mancini R, Pisani T, Alderisio M and Vecchione A: Msh2, Mlh1, Fhit, p53, Bcl-2, and Bax expression in invasive and in situ squamous cell carcinoma of the uterine cervix. Clin Cancer Res 6: 3600-3606, 2000.

21. Murata H, Khattar NH, Kang Y, Gu L and Li GM: Genetic and epigenetic modification of mismatch repair genes hMSH2 and hMLH1 in sporadic breast cancer with microsatellite instability. Oncogene 21: 5696-5703, 2002.

22. Hardisson D, Moreno-Bueno G, Sanchez L, Sarrio D, Suarez A, Calero $\mathrm{F}$ and Palacios J: Tissue microarray immunohistochemical expression analysis of mismatch repair (hMLH1 and hMSH2 genes) in endometrial carcinoma and atypical endometrial hyperplasia: relationship with microsatellite instability. Mod Pathol 16: 1148-1158, 2003.

23. Murata H, Khattar NH, Gu L and Li GM: Roles of mismatch repair proteins hMSH2 and hMLH1 in the development of sporadic breast cancer. Cancer Lett 223: 143-150, 2005.

24. Son BH, Ahn SH, Ko CD, Ka IW, Gong GY and Kim JC: Significance of mismatch repair protein expression in the chemotherapeutic response of sporadic invasive ductal carcinoma of the breast. Breast J 10: 20-26, 2004.

25. Cheah PL and Looi LM: P53 immunohistochemical expression: messages in cervical carcinogenesis. Pathology 34: 326-331, 2002.

26. Scherer SJ, Seib T, Seitz G, Dooley S and Welter C: Isolation and characterization of the human mismatch repair gene hMSH2 promoter region. Hum Genet 97: 114-116, 1996. 